\title{
Distinct Contributions of Hippocampal NMDA and AMPA Receptors to Encoding and Retrieval of One-Trial Place Memory
}

\author{
Tobias Bast, Bruno M. da Silva, and Richard G. M. Morris \\ Laboratory for Cognitive Neuroscience, Division of Neuroscience, University of Edinburgh, Edinburgh EH8 9JZ, United Kingdom
}

\begin{abstract}
Allocentric place memory may serve to specify the context of events stored in human episodic memory. Recently, our laboratory demonstrated that, analogous to event-place associations in episodic memory, rats could associate, within one trial, a specific food flavor with an allocentrically defined place in an open arena. Encoding, but not retrieval, of such flavor-place associations required hippocampal NMDA receptors; retrieval depended on hippocampal AMPA receptors. This might have partly reflected the contributions of these receptors to encoding and retrieval of one-trial place, rather than flavor-place, memory. Therefore, the present study developed a food-reinforced arena paradigm to study encoding and retrieval of one-trial allocentric place memory in rats; memory relied on visuospatial information and declined with increasing retention delay, still being significant after $6 \mathrm{~h}$, the longest delay tested (experiments 1 and 2). Hippocampal infusion of the NMDA receptor antagonist D-AP-5 blocked encoding without affecting retrieval; hippocampal infusion of the AMPA receptor antagonist CNQX impaired retrieval (experiment 3). Finally, we confirmed that the D-AP-5 infusions selectively blocked induction of long-term potentiation, a form of synaptic plasticity, whereas $\mathrm{CNQX}$ impaired fast excitatory transmission, at perforant-path dentate gyrus synapses in the dorsal hippocampus in vivo (experiment 4). Our results support that encoding, but not retrieval, of one-trial allocentric place memory requires the NMDA receptor-dependent induction of hippocampal synaptic plasticity, whereas retrieval depends on AMPA receptor-mediated fast excitatory hippocampal transmission. The contributions of hippocampal NMDA and AMPA receptors to one-trial allocentric place memory may be central to episodic memory and related episodic-like forms of memory in rats.
\end{abstract}

Key words: allocentric spatial learning; hippocampus; synaptic plasticity; NMDA; microinfusions; episodic-like memory

\section{Introduction}

There is growing interest in neurobiological substrates relevant to human episodic memory, the memory of unique personally experienced events (Tulving, 2002). Allocentric place memory may be central to episodic memory, for example, to specify the context of remembered events (Gaffan, 1991; Burgess et al., 2002; Nadel and Hardt, 2004) and is amenable to testing in rodent species suitable for neurobiological investigations (Bures and Fenton, 2000; Aggleton and Pearce, 2001). Inspired by experiments using food-caching behavior to demonstrate episodic-like memory in scrub jays (Clayton and Dickinson, 1998), a recent study from our laboratory (Day et al., 2003) introduced a new apparatus, the "event arena" (see Fig. $1 \mathrm{~A}$ ), in which rats may find food buried in

Received Feb. 21, 2005; revised April 14, 2005; accepted May 4, 2005.

This work was supported by European Framework V and Medical Research Council Programme grants (R.G.M.M.). B.M.d.S. was supported by a PhD scholarship from the Fundação para a Ciência e Tecnologia, Portugal. We are grateful to Richard Watson for animal care, Jane Knox for histology, and Patrick Spooner for technical support. Paul Dudchenko and Matt Van der Meer kindly lent us their night-vision goggles. We also thank Steve Martin for introducing T.B. to in vivo electrophysiology, Ben Yee for statistical consultation, and Steve Martin, Marie Pezze, and Emma Wood for discussions on this manuscript. The present data have been published in abstract form (Bast et al., 2004a,b).

Correspondence should be addressed to Dr. Tobias Bast, Laboratory for Cognitive Neuroscience, Division of Neuroscience, University of Edinburgh, 1 George Square, Edinburgh EH8 9JZ, UK. E-mail: T.Bast@ed.ac.uk. D01:10.1523/JNEUROSCI.0698-05.2005

Copyright $\odot 2005$ Society for Neuroscience $\quad$ 0270-6474/05/255845-12\$15.00/0 sand in any one of many places. Analogous to the event-place associations of episodic memory, rats could associate flavors with the places where they found food of that flavor in single specific episodes. The flavor later served as recall cue for the place where additional food of the same flavor could be obtained. Blockade of hippocampal NMDA receptors impaired encoding, but not retrieval, of such flavor-place paired associates, whereas antagonizing hippocampal AMPA receptors impaired retrieval. The possibility that these effects may partly reflect interference with encoding and retrieval of one-trial allocentric place, rather than flavor-place, memory deserves careful consideration.

Many theoretical models emphasize the importance of the hippocampus for rapid encoding and subsequent retrieval of various types of "relational" memory, including allocentric place memory, that require representations of mutual relationships between multiple features (O'Keefe and Nadel, 1978; O'Reilly and Rudy, 2001; Morris et al., 2003; Wiltgen and Fanselow, 2003; Eichenbaum, 2004; Matus-Amat et al., 2004; Nakazawa et al., 2004). According to these models, encoding of one-trial place memory requires the induction of hippocampal long-term synaptic plasticity, mediated by NMDA receptors (Bliss and Collingridge, 1993; Martin et al., 2000), to conjoin a feature configuration defining a place into a memory representation. Retrieval requires fast excitatory transmission through hippocampal syn- 
apses, essentially mediated by AMPA receptors (Davies and Collingridge, 1989; Lambert and Jones, 1990), to activate the stored place representation after perceiving elements of the feature configuration. Alternatively, it has been suggested that the neural representation of trial-specific places in familiar environments over minutes to hours may not require hippocampal NMDA receptors (Shapiro and O'Connor, 1992; Caramanos and Shapiro, 1994; Kesner and Rolls, 2001).

The present experiments include an examination of the contributions of hippocampal NMDA and AMPA receptors to encoding and retrieval of one-trial place memory. First, we developed and characterized a food-reinforced task for the separate study of the encoding and retrieval of one-trial allocentric place memory in the event arena (experiments 1 and 2). Second, we examined the effects of intrahippocampal infusions of AP-5 or CNQX, competitive antagonists at the NMDA and AMPA receptor, respectively (Watkins et al., 1990), on encoding and retrieval of one-trial place memory in this task (experiment 3). Third, we conducted electrophysiological measurements to establish that, if infused exactly as in the behavioral experiment, AP-5 selectively blocks the induction of synaptic plasticity and CNQX reduces fast excitatory synaptic transmission in the hippocampus in vivo (experiment 4).

\section{Materials and Methods}

\section{Experiments 1 and 2: development and characterization of the} novel one-trial place memory task

The task was designed to enable the study of the neural substrates of encoding and retrieval of one-trial allocentric place memory. This requires robust measures of place memory for discrete trials and a separation of encoding and retrieval phases by several minutes to allow, for example, intracerebral drug infusions and appropriate drug diffusion between the phases. Moreover, to enable a direct comparison, the procedural requirements of the task should be similar to the previously developed flavor-place memory protocol (Day et al., 2003). The present protocol has similarities to food-reinforced place memory paradigms for rats in the "cheeseboard apparatus" developed by Kesner and colleagues (Kesner et al., 1989; Gilbert et al., 1998, 2001; Kirwan et al., 2005) and to paradigms developed for birds (Healy and Krebs, 1992; Clayton and Krebs, 1994). Our protocol comprised one trial per day consisting of two phases: (1) an encoding phase, in which the rats had to search the arena to find food in a trial-specific place and to encode this place in memory; and (2) after a delay of between 5 and $360 \mathrm{~min}$, a retrieval phase, in which the rats could use one-trial place memory to find food in the same place as in the preceding encoding phase (Fig. $1 B$ ). A key aspect of the task is the use of different places across days to enable the successive examination of one-trial encoding and retrieval across a range of conditions in withinsubjects designs.

Subjects. Thirty-one adult male Lister Hooded rats (Charles River, Margate, UK) were used for experiments $1(n=15)$ and $2(n=16)$. They were housed singly in a temperature $\left(20-23^{\circ} \mathrm{C}\right)$-controlled and humidity (40-55\%)-controlled room with an artificial light/dark cycle (lights on 7:00 A.M. to 7:00 P.M.). The rats had ad libitum access to water and were fed a restricted diet (18-24 g per day of standard rat chow, RM1; Special Diet Services, Witham, Essex, UK) to maintain them at $\sim 85 \%$ of their free-feeding weight estimated according to a previously established growth curve. They weighed $200-250 \mathrm{~g}$ and were $8-10$ weeks old at the beginning of the food restriction. Before the start of experiments, all rats
B

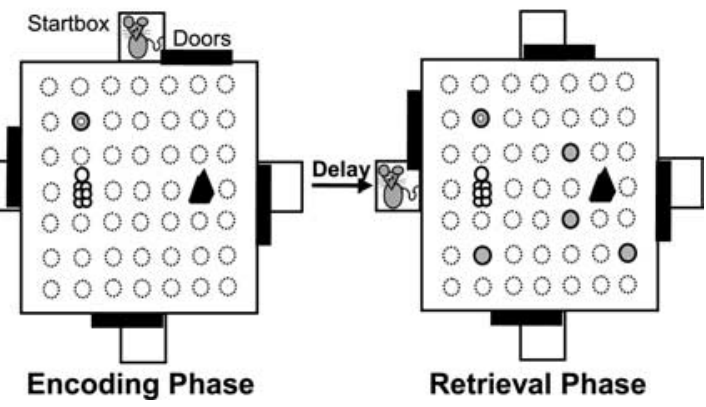

Figure 1. The one-trial place memory task. $A$, Open arena (event arena) used for the task. The arena floor has a $7 \times 7$ grid of circular holes covered by lids that can be removed to insert sandwells. $\boldsymbol{B}, A$ trial comprises an encoding and a retrieval phase. In the ncoding phase, the rat must search for food reward (white dot) buried in a sandwell (filled circle) in a trial-specific place; all other memory according to a win-stay rule. Start positions for encoding and retrieval phases are different requiring allocentric place were habituated to handling by the experimenter. All experimental procedures were conducted during the light phase of the cycle. The Principles of Laboratory Animal Care (National Institutes of Health publication number 86-23, revised 1985) and Home Office regulations for animal experimentation were followed (Project License number 60/2484).

Apparatus. The arena $(1.6 \times 1.6 \mathrm{~m})$ had a $7 \times 7$ grid of 49 circular holes covered by plastic lids. Sandwells ( $6 \mathrm{~cm}$ diameter, $3.5 \mathrm{~cm}$ deep) could be put in these locations, so that their edges were plane with the arena surface. The arena surface stood $75 \mathrm{~cm}$ above the floor and had four walls of clear Perspex (30 cm high). In the center of each wall was a rectangleshaped entrance with a sliding door and a start box $(25 \times 25 \times 25 \mathrm{~cm})$ made from clear Perspex behind it. The second and sixth holes in row 4 were each covered by a landmark, a stack of golf balls and a pyramid, and the arena floor was covered by a thin layer of sawdust. Excepting the addition of sawdust, this arena was identical to the one used previously for the flavor-place task. It was placed in a rectangular test room $(2.6 \times$ $4 \mathrm{~m}$ ) with white walls and could be accessed via two gray doors in the two short walls. One door led to the corridor via which the rats were brought into the test room. A "holding area," where rats could be kept in their home cages before and after trials and during delay phases, was located next to this door, separated from the rest of the room by a gray divider wall. The other door gave access to a control room with a personal computer and a video recorder, both of which were connected to a wide-angle video camera mounted at the ceiling above the arena. The personal computer ran dedicated Labview (National Instruments, Austin, TX) software (P. Spooner, University of Edinburgh, Edinburgh, UK) to monitor trials and to take time measurements, in particular the dig time at different sandwells (see below, Measures of one-trial place memory), and for remote control of start-box doors. The video recorder was used to tape the trials. Three-dimensional cues (star-shaped, ball-shaped, and cubic lampshades of different colors) were mounted on the test room walls and the divider wall; one long wall was decorated with a pattern of big black rectangles and white stripes, and one short wall had a poster with black spots on a white ground on it. Normally, the test room was moderately illuminated (100 lux) by wall-mounted halogen lamps. For tests in darkness (i.e., excluding light frequencies within the rats' visual spectrum), an infrared light source (VISO10IR; Voltek, Stafford, Staffordshire, UK) mounted at the ceiling close to the infrared-sensitive camera provided the only illumination, and the experimenter wore infrared-sensitive night-vision goggles (Cobra Optics, Henfield, West Sussex, UK). The test room was maintained at $\sim 22^{\circ} \mathrm{C}$ by ceiling ventilation.

The sandwells were filled with bird sand (Trilcot, Lincs, UK) up to $0.5-1 \mathrm{~cm}$ below the edge. One-half pellets $(500 \mathrm{mg})$ of standard rodent food (Bio-Serve, Frenchtown, NJ) were used as food reward. The sand was adulterated with thoroughly ground food pellets $(23 \mathrm{~g}$ per $2.5 \mathrm{~kg}$ of sand), to reduce the possibility that rats use food odor to differentiate 
between correct and novel sandwells in the retrieval phase of the trials (see below, One-trial place memory protocol).

Shaping and habituation. During week 1 of food restriction, rats were shaped to dig for food in sandwells placed in their home cages. In week 2, they were habituated to the test environment and trained to search and dig for food in the arena. On day 1 of habituation, the rats were put into the arena for 5 min with no sandwell in place and all holes closed. For days $2-6$, they received one daily habituation trial. In habituation trials, the rat was put in a start box and, after $20 \mathrm{~s}$, allowed access to the arena. The rats started from a different start box each day, so that they had started from all four boxes at least once by the end of the habituation period. In the first habituation trial, one sandwell with one-half of a pellet of food buried near the surface was placed in the center location of the arena. In the following habituation trials, one sandwell with the one-half pellet deeply buried on the bottom was in the location immediately in front of the start box opposite to the one from which the rat started the trial. At the end of the $5 \mathrm{~d}$ habituation period, all rats readily searched and dug for food in the arena, so that a complete habituation trial would typically take $1.5-5 \mathrm{~min}$ (including the $20 \mathrm{~s}$ in the start box and the $60 \mathrm{~s}$ allowed to eat the food).

One-trial place memory protocol. Trials were always separated by at least $1 \mathrm{~d}$, with five to seven trials per week. The trials started with the encoding phase: the rat was put in a start box and after $20 \mathrm{~s}$ was allowed access to the arena. Once the animal had entered the arena, the access door was closed preventing reentry of the animal to the start box. In the encoding phase, the rat had to search for an open sandwell in one particular location and to dig to retrieve the buried food reward. All other locations were closed and covered with sawdust. After the rat had retrieved the food, it was allowed $60 \mathrm{~s}$ to eat the reward and then replaced in its cage in the holding area for a delay period until the start of the retrieval phase. The retrieval phase started with the rat being put into a different start box from the one used at the beginning of the encoding phase [to encourage allocentric orientation based on relationships among multiple visual cues (Eichenbaum et al., 1990)] for $30 \mathrm{~s}$ until the door was opened. In the retrieval phase, the rat could find food in a sandwell in the same location as in the encoding phase (the "correct" location), but four additional sandwells, without reward, were open in four "novel" locations. The rat was returned to its cage $60 \mathrm{~s}$ after it had retrieved the food. During standard trials, the food reward in the retrieval phase was buried in the correct sandwell as in the encoding phase. During probe trials, none of the five sandwells in the retrieval phase contained a reward, and the rat was left searching and digging in the sandwells for a total of $60 \mathrm{~s}$ (counted from the moment it had completely left the start box). After $60 \mathrm{~s}$, the experimenter entered the room and put reward on the surface of the correct sandwell, so that the rat could retrieve it. The purpose of probe trials was to obtain a "dig-time" measure (see below) and to make the use of olfactory cues emanating from the food reward impossible.

Correct and novel locations were changed daily; locations in a trial were never directly adjacent, and they were chosen so that the different quadrants, as well as central and peripheral regions of the arena, were equally associated with correct or novel locations over days. The four locations forming a triangle in front of each start box were never used (except for habituation; see above), because of the high probability that the rat would dig in these locations just by chance when exiting the start box. Because pilot tests (T. Bast, unpublished observations) suggested that the proximity of the sandwells to the rat's start box influences the first choice, all four start boxes were used in a counterbalanced way. To minimize the possibility that rats could use odor traces to find food, the sand used in the different locations was mixed between phases and trials, and the sawdust was whirled between phases and rats.

Measures of one-trial place memory. Measures of one-trial place memory taken during the retrieval phase were (1) the rat's first choice (i.e., in which sandwell it dug first), (2) errors (i.e., the total number of sandwells in novel locations in which the rat dug before digging in the sandwell in the correct location), and (3) the dig time at correct and novel sandwells during the $60 \mathrm{~s}$ retrieval phase in probe trials. "Digging" was defined as the rat putting both front paws on or into the sand with the snout directed downward to the sand. In addition to scoring digging based on the video image, the sandwells were checked for traces of digging: a bump in the sand or sand spread around the sandwell reflected that the animal had dug at a given location. To normalize dig-time measures, a rat's dig time at a sandwell was expressed as a percentage of the overall dig time during the $60 \mathrm{~s}$ retrieval phase of the probe trial (percentage of dig time at sandwell). The values expected based on chance were $20 \%$ of the first choices and of the total dig time at each sandwell and an average number of two errors [compare Healy and Krebs (1992) and Clayton and Krebs (1994)].

Experimental design. Experiment 1 used 15 rats to develop the novel one-trial place memory protocol and to establish that performance would be sufficiently robust for the later drug infusion studies. After shaping and habituation, the 15 rats had first been subjected to 50 trials (1 trial per day) of the previously described flavor-place paired-associate protocol, as part of ongoing efforts to clarify factors influencing performance in different event-arena protocols. In experiment 1 , rats were subjected to 18 trials ( 1 trial per day) with a 5 min delay between the encoding and retrieval phases. Trials $1-16$ and 18 were standard training trials; trial 17 was a probe trial. Before moving on to the surgery for the infusion studies of experiment 3 , the 15 rats were first subjected to a few additional trials to ensure that, as required for the infusion studies, onetrial place memory persists over a delay longer than $5 \mathrm{~min}$. For this purpose, performance was compared at a 5 and 45 min delay in a counterbalanced within-subjects design. The rats were subjected to six trials, with the delay alternating between 5 and $45 \mathrm{~min}$. Trials 3 and 6 were probe trials.

Experiment 2 used 16 naive rats to replicate the initial task acquisition and to characterize thoroughly factors underlying task performance. It was subdivided into successive examinations of: (1) task acquisition as in experiment 1 (excepting with experimentally naive animals); (2) delay dependence of one-trial place memory; (3) effects of arena rotation between encoding and retrieval; and (4) effects of darkness during retrieval.

Experiment 2a started immediately after shaping and habituation of the rats and comprised 16 standard training trials followed by one probe trial, with a 5 min delay between encoding and retrieval. These 17 trials were run exactly as in experiment 1 , using the same correct and novel sandwell locations. Experiment $2 \mathrm{~b}$ thoroughly examined the delay dependence of one-trial place memory in the novel task. For this purpose, performance measures were compared in trials with a delay of 5, 60, 180, and $360 \mathrm{~min}$ between the encoding and retrieval phases in a counterbalanced within-subjects design. The experiment was run in two series; each series comprised four standard training trials at each delay, followed by pairs of alternating standard and probe trials at each of the four delays. Experiment $2 \mathrm{c}$ examined whether the rats' performance may have relied on cryptic odor traces left on the arena surface. It was run in two series, with series 1 run before and series 2 run after the second series of experiment $2 \mathrm{~b}$, allowing a direct comparison of the two experiments. In Experiment $2 c$, performance was tested at a 20 and 360 min delay, with the symmetric arena rotated by 90 or $180^{\circ}$ between the encoding and retrieval phases; the configuration of intra-arena landmarks and extraarena landmarks was kept constant. If rats relied on cryptic odor cues on the arena surface, performance should be disrupted by arena rotation. Each series in experiment $2 \mathrm{c}$ comprised one pair of standard and probe trials for the 20 and the 360 min delay, with the order of the two delays counterbalanced. Finally, experiment $2 \mathrm{~d}$ examined the effects of darkness during retrieval to verify that normal task performance relied on visuospatial cues. To habituate the rats to sudden lighting changes, they were subjected to two standard training trials with a 5 min delay during which the test room (including the holding area) was dark. After this habituation, probe trials (separated by an additional standard training trial with 5 min delay in darkness) were conducted under two different conditions in a counterbalanced within-subjects design. In one condition, the retrieval phase was conducted in light and in the second condition in darkness. In both conditions, the delay was $20 \mathrm{~min}$ (because this delay was used in the infusion studies) and it was dark during the delay (to control for a possibly startling effect of sudden lighting changes). Only one series of such probe trials was conducted, because repeated retrieval phases in darkness might have encouraged the rat to acquire nonvisual strategies (such as orientation based on localized sound sources). 
Statistical analysis. Paired Student's $t$ tests or repeated-measures ANOVA were used to analyze the influence of within-subjects variables on behavioral measures, unless stated otherwise. Fisher's protected least significant difference (PLSD) post hoc tests were used to further examine main effects of the ANOVA. Paired Student's $t$ tests were used to compare performance measures to the values expected based on chance. The level of significance was set at $p<0.05$ for all analyses. Data are presented as mean \pm 1 SEM.

Experiment 3: effects of hippocampal AP-5 or CNQX infusions on encoding and retrieval of one-trial place memory

The significance of hippocampal NMDA and AMPA receptors for encoding and retrieval of one-trial place memory was tested by specifically blocking these receptors during different phases of the one-trial place memory task. We first tested the effects of hippocampal NMDA receptor blockade by AP- 5 on both encoding and retrieval and then the effects of AMPA receptor blockade by CNQX on retrieval. For reasons explained under Experimental design above, the effects of AMPA receptor blockade on encoding were not tested.

Subjects. The 15 rats from experiment 1, $\sim 6.5$ months old after its completion, received bilateral implantation of infusion guide cannulas. One rat was excluded after surgery because of bad health, leaving 14 cannulated rats. Because of their pretraining, these rats were equally familiar with the different sandwell locations as the rats used previously to examine the effects of hippocampal NMDA and AMPA receptor blockade on one-trial flavor-place memory, allowing a direct comparison. The rats were kept on a moderate food-deprivation schedule and housed as described for experiments 1 and 2 but had ad libitum access to food from $1 \mathrm{~d}$ before until $2 \mathrm{~d}$ after surgery.

Implantation of infusion guide cannulas. One day before until $3 \mathrm{~d}$ after surgery, animals received an analgesic in their drinking water (Rimadyl Large Animal Solution; $2 \mathrm{ml} / \mathrm{L}$ ). Anesthesia was induced with 5\% halothane and maintained with $1-3 \%$ halothane, delivered in oxygen. The rats were placed in a stereotaxic frame, the scalp was incised to expose the skull, and bregma and gamma were aligned in the same horizontal plane. Infusion guide cannulas (26 gauge) with stylets (33 gauge; C315; Plastics One, Bilaney, UK), which should prevent occlusion of the guides and which were secured to them by plastic caps, were implanted through small holes drilled into the skull. The stylet tips projected $0.5 \mathrm{~mm}$ from the end of the guide and were aimed at the following coordinates above the posterior dorsal hippocampus: $4.5 \mathrm{~mm}$ posterior and $3.0 \mathrm{~mm}$ lateral from bregma and $3.0 \mathrm{~mm}$ ventral from the dura. These coordinates were used in previous studies examining the effects of hippocampal microinfusions in place and flavor-place memory tasks in our laboratory (Riedel et al., 1999; Steele and Morris, 1999; Day et al., 2003). Guide cannulas were fixed to the skull with dental cement and stainless steel screws. After surgery, rats had a recovery period of $9-10 \mathrm{~d}$ before the start of any additional behavioral procedures. During this period, the rats were habituated to the restraint necessary for the hippocampal infusions.

Intrahippocampal microinfusions and drugs. For the bilateral infusion in the behavioral experiments, rats were restrained manually; infusions into both hemispheres were performed simultaneously. The stylets in the guide cannulas were replaced by infusion cannulas (33 gauge; C315; Plastics One) connected to microsyringes in a microinfusion pump via flexible polyvinyl chloride tubing. The tips of the infusion cannulas projected $0.5 \mathrm{~mm}$ beyond the end of the guides. A volume of $1 \mu \mathrm{l}$ per cannula was infused at a rate of $0.4 \mu \mathrm{l} / \mathrm{min}$. To allow for absorption of the infusion bolus by the brain tissue, the infusion cannulas were then left in place for $1 \mathrm{~min}$ before being replaced by the stylets.

Phosphate-buffered artificial CSF (ACSF) (in mM: $150 \mathrm{Na}^{+}, 3 \mathrm{~K}^{+}, 1.4$ $\mathrm{Ca}^{2+}, 0.8 \mathrm{Mg}^{2+}, 155 \mathrm{Cl}^{-}, 0.2 \mathrm{H}_{2} \mathrm{PO}_{4}{ }^{-}, 0.8 \mathrm{HPO}_{4}{ }^{2-}, \mathrm{pH}$ 7.2) was used as infusion vehicle and for control infusions. Drug concentrations for infusions were $3 \mathrm{~mm}$ of the competitive AMPA/kainate receptor antagonist CNQX (disodium salt; $\mathrm{C}_{9} \mathrm{H}_{2} \mathrm{~N}_{4} \mathrm{O}_{4} \mathrm{Na}_{2} \mathrm{x}_{1} \mathrm{H}_{2} \mathrm{O}$; Tocris, Bristol, UK) (corresponding to $0.89 \mu \mathrm{g} / \mu \mathrm{l}$ ) or $30 \mathrm{~mm}$ of the competitive NMDA receptor antagonist D-AP-5 $\left(\mathrm{C}_{5} \mathrm{H}_{12} \mathrm{NO}_{5} \mathrm{P}\right.$; Tocris) (corresponding to 5.9 $\mu \mathrm{g} / \mu \mathrm{l})$. The solution of CNQX was facilitated by slight sonification. The $\mathrm{pH}$ of the drug solutions was adjusted to 7.2 by the addition of concen- trated phosphoric acid (for CNQX) or of $1 \mathrm{M} \mathrm{NaOH}$ solution (for D-AP5). Both ACSF and drug solutions were prepared in larger quantities, divided into $400-800 \mu \mathrm{l}$ aliquots, and kept frozen at $-20^{\circ} \mathrm{C}$ until use. The CNQX solution was slightly sonicated after thawing.

Histology. At the completion of the experiments, rats were anesthetized with an overdose of Euthatal (Harlow, Essex, UK) and perfused transcardially with saline, followed by $4 \%$ formaldehyde solution to fix the brain tissue. Brains were extracted from the skull, postfixed in $4 \%$ formaldehyde solution, and cut into $30 \mu \mathrm{m}$ coronal sections on a freezing microtome. Every third section through the area of interest was mounted on slides and stained with cresyl violet. The sections were examined with a light microscope under 20 -fold magnification to verify cannula placements and draw them onto plates from the atlas of Paxinos and Watson (1998).

Experimental design. The one-trial place memory task was run as described for experiments 1 and 2. The delay between the encoding and retrieval phases and the time points for intrahippocampal infusions were chosen to be identical to those in the studies on flavor-place memory (Day et al., 2003): the delay was $20 \mathrm{~min}$, and infusions started $15 \mathrm{~min}$ before the encoding phase or $15 \mathrm{~min}$ before the retrieval phase. Infusions were conducted in the holding area of the experimental room.

After recovery from surgery, the rats were subjected to four standard training trials (postsurgery habituation trials) to ascertain that one-trial place memory was still above chance and unaffected by mock infusions. Before the encoding or retrieval phase of the third and fourth trials, rats received mock infusions (eight rats before encoding of trial 3 and retrieval of trial 4 and seven rats vice versa). A mock infusion was identical to a real infusion, except that syringes and tubing were empty.

The effects of hippocampal drug and ACSF infusions on encoding and retrieval of one-trial place memory were studied in a within-subjects design, with the order of the different infusion conditions counterbalanced between animals. Infusion days were alternated with days without infusion. On infusion days, probe trials were conducted, whereas on the days without infusion, standard training trials were run. Experiment $3 \mathrm{a}$ examined the effects of hippocampal infusion of the NMDA receptor antagonist AP- 5 before encoding and retrieval (four infusion conditions: AP-5 before encoding, AP- 5 before retrieval, ACSF before encoding, ACSF before retrieval). This experiment revealed that NMDA receptor blockade disrupted encoding but not retrieval. This implied that AMPA receptor blockade would also disrupt encoding, because NMDA receptor-mediated induction of synaptic plasticity requires AMPA receptor-mediated postsynaptic depolarization (Bliss and Collingridge, 1993). The interesting outstanding issue, however, was whether, in contrast to NMDA receptor blockade, AMPA receptor blockade would also impair retrieval, as predicted by the theoretical positions described in the Introduction. Moreover, limiting the number of infusion conditions could help to decrease the risk of problems associated with many intracerebral infusions (gliosis, infections, cannula blockade) while increasing the statistical power of the design. Therefore, experiment $3 \mathrm{~b}$ examined the effects of hippocampal infusion of the AMPA receptor antagonist CNQX only before retrieval (two infusion conditions: CNQX before retrieval, ACSF before retrieval).

Statistical analysis. Statistical analysis was conducted similar to experiments 1 and 2, with infusion conditions as an additional within-subjects factor. Based on the results of experiments 1 and 2, analysis mainly focused on the dig-time measure.

\section{Experiment 4: effects of hippocampal AP-5 or CNQX infusions on} synaptic transmission and plasticity

Different effects on hippocampal synaptic transmission and plasticity may underlie the distinct effects of hippocampal AP-5 and CNQX infusions on encoding and retrieval of one-trial place memory in experiment 3. To substantiate this, we examined the effects of hippocampal AP-5 and CNQX infusions, conducted exactly as in experiment 3, on lowfrequency transmission and long-term potentiation (LTP) at one intrinsic hippocampal connection, the perforant-path dentate gyrus synapses, in anesthetized rats.

Subjects, implantation of infusion guide cannulas, intrahippocampal microinfusions, and drugs. Thirty-nine naive male Lister Hooded rats (250$390 \mathrm{~g}$ and 2-4 months old; Charles River) with ad libitum access to food, 
but otherwise housed and handled as the rats in the previous experiments, were implanted with one infusion guide cannula into the left hemisphere exactly as described for experiment 3 . The plastic pedestal of the guide cannulas was partly cut away before implantation, and the locations for insertion of the stimulating and recording electrodes (see below) were marked on the skull and kept free of dental cement. After surgery, rats were allowed at least $7 \mathrm{~d}$ of recovery before the electrophysiological experiments.

Once the rats were anesthetized for the electrophysiology (see below), the Plastics One stylets were replaced by stylets without a plastic cap, but otherwise identical, to make space for the electrodes and to prevent occlusion of the guide cannulas until infusion. Infusion procedures and drug solutions were as described for experiment 3.

Electrophysiology. Electrophysiological procedures were similar to previous studies from our laboratory (Martin, 1998; Riedel et al., 1999). The rats were anesthetized with urethane $(1.5 \mathrm{~g} / \mathrm{kg}$, i.p.), and their rectal temperature was maintained at $36.2 \pm 0.2^{\circ} \mathrm{C}$. Ipsilateral to the infusion guide, they were stereotaxically implanted with a twisted bipolar stimulating electrode (distance between electrode tips, $0.5-1 \mathrm{~mm}$ ) into the angular bundle of the perforant path and a monopolar recording electrode into the hilus of the dentate gyrus. Electrodes (Teflon-coated platinum90-iridium 10 wire; outer diameter, $112 \mu \mathrm{m}$ ) were aimed at the following coordinates (in $\mathrm{mm}$ ): stimulating electrode: 7.5 posterior and 4.0 lateral from bregma and 2.5 ventral from the dura; recording electrode: 3.5 posterior and 2.0 lateral from bregma and 3.0 ventral from the dura. Recordings were made against a reference electrode placed on the cortex anterior to bregma. Stimulation was applied via a Neurolog stimulus isolator (NL800; AutoMate Scientific, San Francisco, CA). Field EPSPs were amplified and filtered (1 Hz low-frequency cutoff, $5 \mathrm{kHz}$ high-frequency cutoff) by a differential AC amplifier (model 1700; AM Systems, Everett, WA). A personal computer running dedicated Labview software (P. Spooner) was used to control the stimulation and to record $(20,000 \mathrm{~Hz}$ sampling frequency) and analyze EPSPs. The main measure of the evoked response was the slope of the initial rising part (2.0-2.6 or 2.2-2.8 ms after stimulation) of the EPSP. Electrodes were initially positioned $1 \mathrm{~mm}$ dorsal to the target coordinates. Biphasic $0.2 \mathrm{~ms}, 0.5 \mathrm{~mA}$ stimulation was delivered at $0.1 \mathrm{~Hz}$, and the final coordinates of the electrodes were adjusted to record a positive EPSP and to maximize its slope. The slope was aimed to be at least $2 \mathrm{mV} / \mathrm{ms}$ under these conditions, and occasionally the stimulus intensity was increased to maximally $1 \mathrm{~mA}$ to reach this value. After positioning the electrodes, low-frequency test stimulation continued with biphasic $0.1 \mathrm{~ms}$ pulses of the same intensity, delivered at $0.05 \mathrm{~Hz}$ for the rest of the experiment. A tetanus to induce LTP consisted of three trains of 50 biphasic $0.2 \mathrm{~ms}$ pulses at $250 \mathrm{~Hz}$ with $60 \mathrm{~s}$ between trains (overall $2 \mathrm{~min}$ ). In several animals, EEG activity was recorded via the recording electrode in the dentate gyrus and analyzed as described previously (Martin, 2001) to assess the different effects of the infusions on local spontaneous electrical activity. At the end of the experiments, the locations of the electrode tips were marked by a $10 \mathrm{~mA}, 2 \mathrm{~s}$ biphasic pulse to the electrodes and, as described for experiment 3 , rats were perfused and their brains were further processed to verify cannula and electrode placements.

Experimental design. The electrophysiological effects of hippocampal infusions were studied in a between-subjects design. Experiment $4 \mathrm{a}$ compared the effects of hippocampal infusion of CNQX $(n=7)$, AP-5 $(n=$ 7 ), and $\operatorname{ACSF}(n=6)$ on fast excitatory transmission evoked by lowfrequency stimulation. A stable preinfusion baseline was recorded for 20 min before the start of the infusion. Recording continued for $2.5 \mathrm{~h}$ after the start of the infusion. Experiment $4 \mathrm{~b}$ compared the effects of hippocampal AP-5 and ACSF infusion on LTP. Stable preinfusion baseline EPSPs evoked by low-frequency stimulation were recorded for $20 \mathrm{~min}$ until infusion of AP-5 $(n=6)$ or $\operatorname{ACSF}(n=6)$ started. Fifteen minutes after the start of the infusion, the perforant path was tetanized, lowfrequency test stimulation continued, and EPSPs were recorded for an additional $2.5 \mathrm{~h}$. To verify that AP- 5 effects on LTP reflected interference with the induction but not the maintenance or expression of LTP, an additional group (post-AP-5, $n=7$ ) received hippocampal AP-5 infusion, not before tetanization but $5 \mathrm{~min}$ after the end of the tetanus. The timing of the infusions in relation to the tetanus (i.e., 15 min before the tetanus or $5 \mathrm{~min}$ after the tetanus) corresponded to the timing of the infusions in relation to the encoding phase in experiment 3.

Statistical analysis. EPSP slopes were averaged in 5 min blocks and expressed as a percentage of the mean slope during the $20 \mathrm{~min}$ baseline recording (percentage of baseline EPSP slope). Student's $t$ tests or ANOVA were used to analyze the influence of within- and betweensubjects variables. Fisher's PLSD post hoc test was used to further examine main effects of the ANOVA. The level of significance was set at $p<0.05$. Data are presented as mean \pm 1 SEM.

\section{Results \\ Experiment 1}

The rats that were pretrained in the flavor-place memory task rapidly learned the win-stay rule of the place memory task. During the encoding phase, they searched the arena for the single open sandwell, with their heads near the arena floor, whereas in the retrieval phase, they moved relatively quickly to the correct place. After a few training trials, first choices were significantly above and errors were below chance during the retrieval phase (Fig. 2A, left and middle, gray symbols). The percentage of rats making correct first choices increased over the 18 trials (linear regression, percentage first choices vs day; slope, $1.74 ; r=0.64$; $p<0.004$ ) (Fig. 2A, left, gray symbols). Collapsed in three-trial blocks, the first-choice measure was statistically significant above chance after nine training trials (supplemental material 1.1., available at www.jneurosci.org). The mean number of errors decreased throughout the 18 trials $\left(F_{(17,238)}=2.02 ; p<0.02\right)$ and was significantly lower than chance for trials 4,5 , and 7-18 (including the probe trial, trial $\left.17 ; t_{(14)}>2.5 ; p<0.02\right)$ but not trials $1-3$ and $6\left(t_{(14)}<1.5 ; p>0.16\right)$ (Fig. $2 A$, middle, gray symbols). During the retrieval phase of the probe trial, the percentage of dig time at the sandwell in the correct location was nearly four times as high as the average at the sandwells in the four novel locations $\left(t_{(14)}=4.9 ; p<0.001\right)$ (Fig. $2 A$, right, gray symbols). Dig time in the correct sandwell was higher and the average dig time at the novel sandwells was lower than chance $\left(t_{(14)}>4.9 ; p<0.001\right)$.

Before the 15 rats of experiment 1 moved on to the infusion studies of experiment 3, it was demonstrated that they still showed robust place memory when the delay between encoding and retrieval was extended to $45 \mathrm{~min}$ and that there was no significant difference in performance between the 5 - and the 45 -min delay (supplemental material 1.2., available at www.jneurosci. org). A thorough characterization of the delay dependence of one-trial place memory, including additional longer retention delays, was conducted with another batch of rats as part of experiment 2 .

\section{Experiment 2}

Task acquisition (experiment 2a)

After shaping and habituation, the otherwise naive rats learned the rule of the task within a few trials. The performance measures during task acquisition were very similar to those obtained in experiment 1a (Fig. 2A, compare black and gray symbols) (for additional details, see supplemental material, 2.1., available at www.jneurosci.org). A direct comparison of the two data sets by means of ANOVA with experiment as a between-subjects factor did not yield any significant main effect of experiment or an interaction of experiment with any of the within-subjects variables $(F<1)$.

Delay dependence of one-trial place memory (experiment $2 b$ ) Over the longer retention intervals tested, one-trial place memory monotonically declined with an increasing delay between the 
encoding and retrieval phases. This was particularly evident from the dig-time measure obtained during the probe trials at each of the four different delays (Fig. $2 B)$. Overall, ANOVA of the percentage of dig time (average of two probe trials per delay) at the different sandwells yielded a highly significant interaction delay by sandwell type (correct or novel) $\left(F_{(3,45)}=\right.$ 17.3; $p<0.0005)$ : while dig time at the correct well decreased with increasing delay $\left(F_{(3,45)}=17.3 ; p<0.0001\right)$, the average dig time at novel wells increased $\left(F_{(3,45)}=\right.$ $10.2 ; p<0.0001)$, reflecting weaker memory for the correct location at longer delays. Compared with the 5 min delay, dig time was decreased at the correct and increased at the novel sandwells at all other delays tested $(60,180$, and $360 \mathrm{~min} ; p<$ $0.005)$. In addition, dig times at both correct and novel sandwells significantly differed between the 360 and 60 min delay $(p<0.05)$. Nevertheless, at all delays tested, including $360 \mathrm{~min}$, the percentage of dig time was significantly higher at correct than at novel sandwells, as well as higher than chance at the correct sandwell and lower than chance at the novel wells $\left(t_{(15)}>2.4 ; p<0.05\right)$. Inspection of the first-choice and error measure also indicated reduced performance with increasing delays, although statistical analysis failed to reveal a significant influence of delay variation (supplemental material 2.2., available at www.jneurosci.org). The significant delay effect on the dig-time but not on the first-choice or error measure demonstrated that dig time is a more sensitive measure of memory strength. The error and, in particular, first-choice measure show a high variance both between different rats and between different trials, reflecting their dependence on the rat's start box and on the arrangement of correct and novel locations. Also, a high percentage of dig time at a certain sandwell may rather reflect a persistent effort of the rat, than the brief digging that results in scoring a first choice or an error.

Arena rotation between encoding and retrieval (experiment 2c) Performance was normal when the arena was rotated by 90 or $180^{\circ}$ between encoding and retrieval, demonstrating that rats did not rely on cryptic odor traces on the arena surface. Dig-time preference for the correct sandwells (Fig. 2C) was comparable with experiment $2 \mathrm{~b}$ (without arena rotation) (Fig. 2B). Again, analysis of the dig time revealed a clear delay effect. ANOVA of the percentage of dig time (average of two probe trials at both delays) at the different sandwells yielded a highly significant interaction delay by sandwell type (correct or novel) $\left(F_{(1,15)}=15.1\right.$; $p<0.005)$ : dig time at the correct well was lower and dig time at the novel wells was higher at the $360 \mathrm{~min}$ than at the $20 \mathrm{~min}$ delay

\section{A Task acquisition}
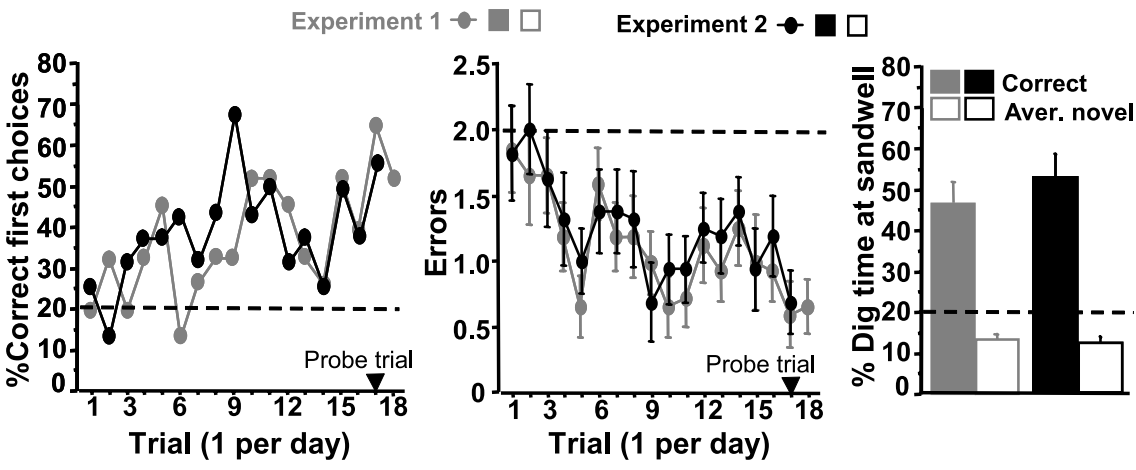

B Delay dependence

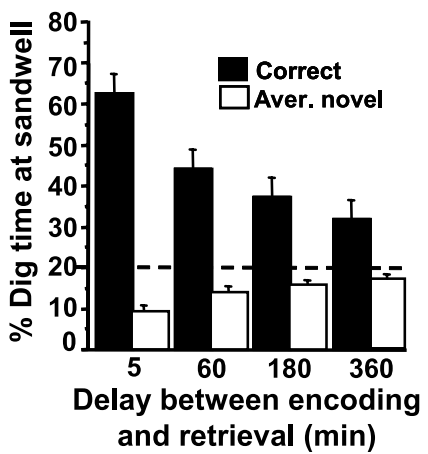

C Arena rotation
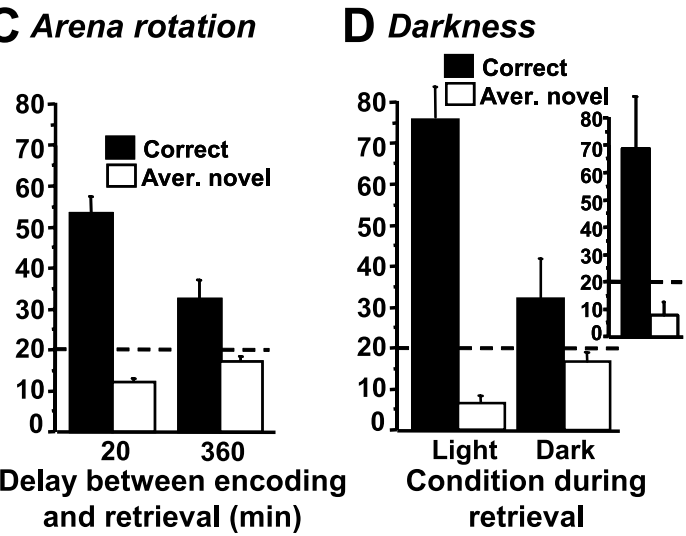

Figure 2. Development and characterization of the novel one-trial place memory task (experiments 1 and 2). Stippled horizontal lines indicate chance values of performance measures. The rats in experiment 1 (gray symbols; $n=15$ ) were previously trained on a flavor-place memory task, whereas the rats in experiment 2 (black symbols; $n=16$ ) were only shaped to dig in percentage of correct first choices (percentage of rats digging first in the correct sandwell; left) and errors (number of novel wells in which rats dug before digging in the correct one; mean \pm 1 SEM; middle) for the initial training trials conducted with a 5 min to calculate the percentage of dig time at the correct sandwell and the average percentage of dig time at novel sandwells (mean \pm 1SEM; right). $\boldsymbol{B}$, Delay dependence of one-trial place memory (experiment $2 \mathrm{~b}$ ). The rats were trained with 5, 20,60, 180, and 360 at the four different delays are depicted (average of two probe trials; mean $\pm 1 \mathrm{SEM}$ ). $\boldsymbol{C}$, Arena rotation between encoding and intra-arena landmarks and the extra-arena room cues was kept constant (six trials at each delay: four standard training trials and mean \pm 1 SEM). $\boldsymbol{D}$, Darkness during retrieval (experiment $2 \mathrm{~d}$ ). To demonstrate the requirement of visuospatial cues, retrieval in darkness was compared with retrieval in light (one probe trial for each condition) at a 20 min delay. The dig-time measure in any sandwell during darkness but performed normally in light (inset). That the average percentage of dig time in the dark condition (right; $32.3 \pm 10.1 \%$ ) is numerically higher than chance is essentially attributable to a single rat that dug briefly $(1.0 \mathrm{~s})$ in the correct well, without touching the novel wells. $\left(t_{(15)}>3.9 ; p<0.005\right)$. Nevertheless, at both delays, dig time significantly differed between correct and novel sandwells and was higher than chance at the correct sandwell and lower than chance at the novel wells $\left(t_{(15)}>2.5 ; p<0.05\right)$. The delay dependence of performance was also suggested by the first-choice and error measure, although the statistical analysis of these measures was less conclusive (supplemental material 2.3., available at www.jneurosci.org). Finally, a direct comparison of performance measures at the 360 min delay with those obtained at the same delay in experiment $2 \mathrm{~b}$ did not yield any difference $(p>0.8)$. Moreover, performance measures at the $20 \mathrm{~min}$ delay, in particular the dig-time measure, lay between those at the 5 and $60 \mathrm{~min}$ delay in experiment $2 \mathrm{~b}$. 
Darkness during retrieval (experiment $2 d$ )

Darkness during the retrieval phase completely disrupted performance, demonstrating the requirement of visuospatial cues. When it was dark only during the delay but light during the retrieval phase, all rats showed good performance. However, when it was dark during the retrieval phase, 4 rats did not dig in any sandwell, and the other 12 rats dug without discrimination between correct and novel sandwells $\left(t_{(11)}<1.3 ; p>0.25\right)$ (Fig. $2 D$ ). The former four rats performed well in the light (first choices, three of four rats; errors, $0.75 \pm 0.75$; for dig time, see Fig. 2D, inset); a formal statistical analysis of performance measures is not presented because of the small number of rats. For the 12 rats digging both in darkness and in light, ANOVA of the dig-time measure revealed a significant interaction between the lighting condition in the retrieval phase (dark or light) and the sandwell type (correct or novel) $\left(F_{(1,11)}=11.6 ; p<0.01\right)$. Additional comparisons yielded a higher proportion of dig time at the correct well and a lower proportion at novel wells in light compared with darkness $\left(t_{(11)}>3.4 ; p<0.01\right)$. Only in light, but not in darkness, did the percentage of dig time significantly differ between correct and novel sandwells and was higher than chance at the correct sandwell and lower than chance at the novel wells (light: $t_{(11)}>7.2 ; p<0.0001$; darkness: $t_{(11)}<1.3 ; p>0.24$ ). Error and first-choice measures also supported that rats were unable to discriminate between correct and novel sandwells in darkness, but strong statistical conclusions were hampered because there was only one trial for each condition and only 12 rats contributed data for both conditions (supplemental material 2.4., available at www.jneurosci.org).

\section{Additional observations}

In the retrieval phase, rats often passed or crossed sandwells in novel locations but did not dig in them, although briefly interrupting their forward movement. Many rats ate the pellet near the correct sandwell (experiment 1, 5 of 15; experiment 2,14 of 16), and others ate it near one of the two landmarks. Afterward, they often stayed at or returned to the sandwell. During the $60 \mathrm{~s}$ retrieval phase in probe trials, rats would typically spend 10$20 \mathrm{~s}$ digging, with this dig time equally distributed over the entire $60 \mathrm{~s}$ period, and the rest of the time walking around between the different sandwells, inspecting the wells and the environment.

Throughout several months of training, the rats' performance improved, probably reflecting the increasing influence of the win-stay rule of the task on the rats' behavior. For example, in the probe trials of experiment 2d (Fig. 2D) conducted after $\sim 5$ months of training, the percentage of dig time in the correct sandwell (for the control condition, i.e., light during retrieval) was much higher than in the first probe in experiment $2 \mathrm{a}$, conducted after $17 \mathrm{~d}$ of training (Fig. $2 \mathrm{~A}$, right, black symbols). Moreover, after several months of training, the rats were very efficient and had to spend only very little time to retrieve food from the sandwells. This resulted in a decrease in overall dig time in probe trials. For example, in the probe of experiment $2 \mathrm{~d}$, the overall dig time in the control condition was $7.65 \pm 2.28 \mathrm{~s} \mathrm{com-}$ pared with $18.9 \pm 3.65 \mathrm{~s}$ in the probe trial of experiment $2 \mathrm{a}$.

\section{Summary}

The novel protocol yielded robust and statistically reliable abovechance measures of one-trial place memory for discrete trials. One-trial place memory declined monotonically with increasing retention delay but was still significant at a 360 min delay. Furthermore, performance was demonstrated not to rely on cryptic odor or idiothetic cues but to require visuospatial cues. Firstchoice, error, and dig-time measures reflected statistically signif-
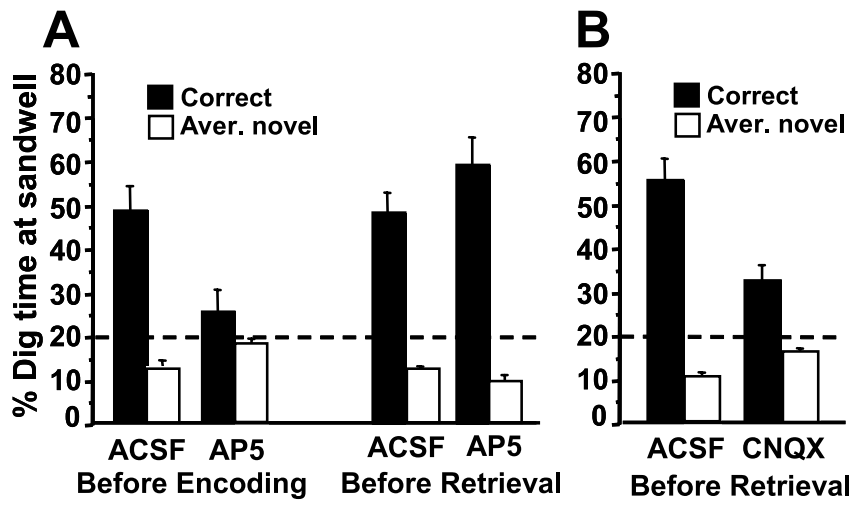

Figure 3. Effects of hippocampal AP-5 and CNQX infusions on encoding and retrieval of one-trial place memory (experiment $3, n=14$ rats). The percentage dig time at correct and novel sandwells (mean $\pm 1 \mathrm{SEM}$ ) in probe trials is presented as a performance measure; stippled horizontal lines indicate chance. $\boldsymbol{A}$, Performance when the NMDA receptor antagonist D-AP-5 (30 mm, $1 \mu \mathrm{l}$ ) or ACSF ( $1 \mu \mathrm{l})$ was infused into the hippocampus $15 \mathrm{~min}$ before the encoding or retrieval phase. $\boldsymbol{B}$, Performance when the AMPA receptor antagonist CNQX ( $3 \mathrm{~mm}$, $1 \mu \mathrm{l})$ or ACSF ( $1 \mu \mathrm{l}$ ) was infused $15 \mathrm{~min}$ before the retrieval phase.

icant performance. Although both error and dig-time measures are continuous values for discrete trials, the dig-time measure was the most consistent measure of one-trial place memory. It showed relatively little interindividual variance (relative SEM in a discrete trial, $\sim 10 \%$, compared with $30 \%$ for the error measure) and little variation between trials with different constellations of correct and novel sandwells. The sensitivity of the dig-time measure as an indicator of memory strength was particularly demonstrated by its gradual alteration with increasing delay between encoding and retrieval.

\section{Experiment 3}

The cannulated rats showed good performance in the four postsurgery habituation trials, during which they were familiarized with the 20 min delay between the encoding and retrieval phase, as well as with the handling required for the infusion experiments. The average number of errors in the two trials with mock infusions $(1.18 \pm 0.21)$ and the two trials without mock infusions $(1.00 \pm 0.16)$ did not differ $\left(t_{(13)}=0.6 ; p>0.56\right)$ and was significantly lower than the chance level $\left(t_{(13)}>3.9 ; p<0.002\right)$.

\section{Effects of hippocampal AP-5 infusions on encoding and retrieval} (experiment $3 a$ )

Hippocampal infusion of the NMDA receptor antagonist AP-5 impaired encoding but not retrieval of one-trial place memory (Fig. 3A). An overall ANOVA of the percentage of dig time at the different sandwells yielded a highly significant interaction between the infusion condition and the sandwell type (i.e., correct or novel; $\left.F_{(3,39)}=6.8 ; p<0.001\right)$. Subsequent separate ANOVAs on the percentage of dig time spent at the correct sandwell, as well as on the average percentage of dig time at the sandwells in novel locations, revealed significant main effects of the infusion condition. When rats received hippocampal AP-5 infusion before encoding, the percentage of dig time spent at the correct sandwell was significantly lower, whereas the average percentage of dig time spent at the sandwells in novel locations was significantly higher $(p<0.01)$, than in the other three conditions, which did not differ $(p>0.16)$. Moreover, when rats received AP-5 before encoding, the percentage of dig time in correct and novel locations was similar and not different from the chance level $\left(t_{(13)}<\right.$ $1.2 ; p>0.25)$. In all other infusion conditions, the percentage of dig time at the correct sandwell was higher than the average per- 
centage of dig time in the novel locations, with the former being significantly higher and the latter being significantly lower than the chance level $\left(t_{(13)}>5.1 ; p<\right.$ $0.0005)$. Although the average number of errors was numerically increased when AP-5 was infused before encoding (1.36 \pm $0.31)$ compared with AP-5 infusion before retrieval $(0.71 \pm 0.24)$ or ACSF infusion before encoding $(1.00 \pm 0.28)$ or retrieval $(0.86 \pm 0.28)$, ANOVA did not yield a main effect of infusion condition on the error measure $\left(F_{(3,39)}=1.0\right)$. However, the average number of errors did not differ significantly from chance when rats received AP-5 before encoding $\left(t_{(13)}=2.1\right.$; $p>0.05)$, but it was lower than chance in all other conditions $\left(t_{(13)}>3.6 ; p<\right.$ 0.005).

\section{Effects of hippocampal CNQX infusion on retrieval (experiment $3 b$ )}

Hippocampal CNQX infusion impaired the retrieval of one-trial place memory (Fig. 3B). An overall ANOVA of the percentage of dig time spent at the different sandwells yielded a highly significant interaction between the infusion condition and the sandwell type $\left(F_{(1,13)}=23.4 ; p<\right.$ $0.0005)$. Subsequent paired $t$ tests revealed that, compared with the ACSF control condition, dig time at the correct sandwell was decreased and dig time at the sandwells in novel locations was increased $\left(t_{(13)}\right.$ $>4.8$; $p<0.0005$ ) when rats received hippocampal CNQX infusion before retrieval. Nevertheless, in both the ACSF and the CNQX infusion conditions, the percentage of dig time at the correct sandwell was higher than the average percentage of dig time in the novel locations $\left(t_{(13)}>3.6 ; p<\right.$ 0.003 ), with the former being significantly higher and the latter being significantly lower than the chance level $\left(t_{(13)}>3.6\right.$; $p<0.003)$. The number of errors was significantly increased in the CNQX (1.36 \pm 0.25$)$ compared with the ACSF (1.00 \pm 0.021 ; $\left.t_{(13)}=2.7 ; p<0.02\right)$ condition, although it was significantly lower than chance in both groups $\left(t_{(13)}>2.5 ; p<0.02\right)$.

Non-mnemonic infusion effects

The effects of the hippocampal drug infusions on nonmnemonic behavioral processes possibly necessary for task performance were assessed by careful observation of the rats' behavior, as well as by analysis of the absolute dig time during the retrieval phase. Hippocampal infusion of AP-5 often resulted in slight ataxia (i.e., slight unsteadiness when moving), which lasted for $\sim 15-20$ min (supplemental material 3.1., available at www. jneurosci.org). Inspection of one-trial place memory performance in individual rats after hippocampal AP-5 infusion did not indicate a relationship between the occurrence or absence of ataxia and performance. CNQX did not result in any sensorimotor impairment apparent during observation of the rats' behavior. Moreover, neither AP-5 nor CNQX appeared to affect motivational or sensorimotor processes underlying digging. Analysis
Experiment 4A
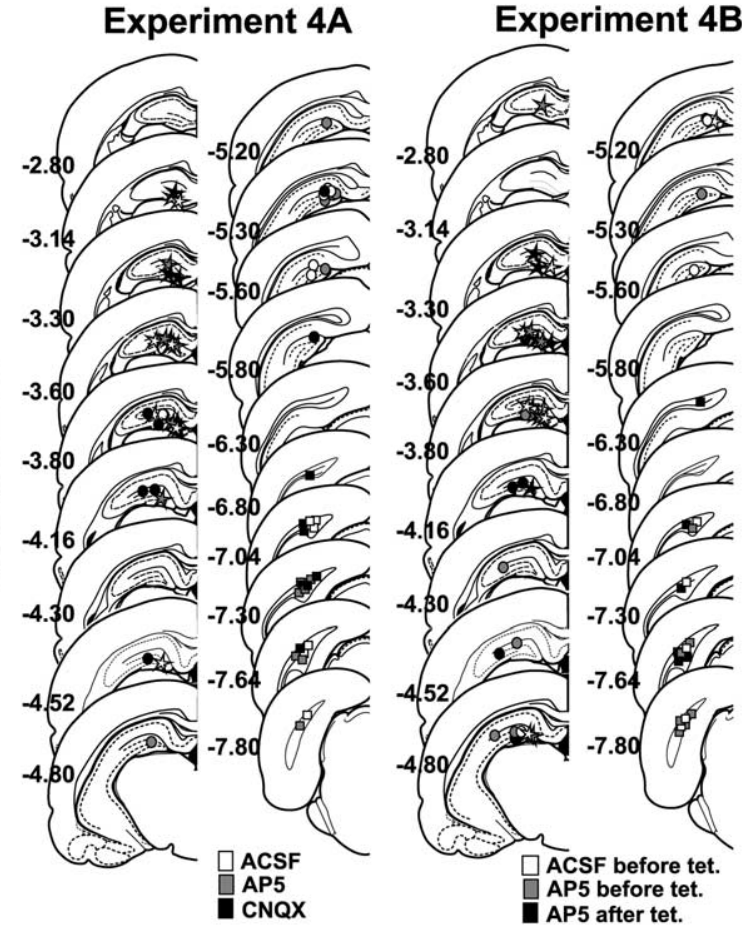

AP5 before tet.
AP5 after tet.

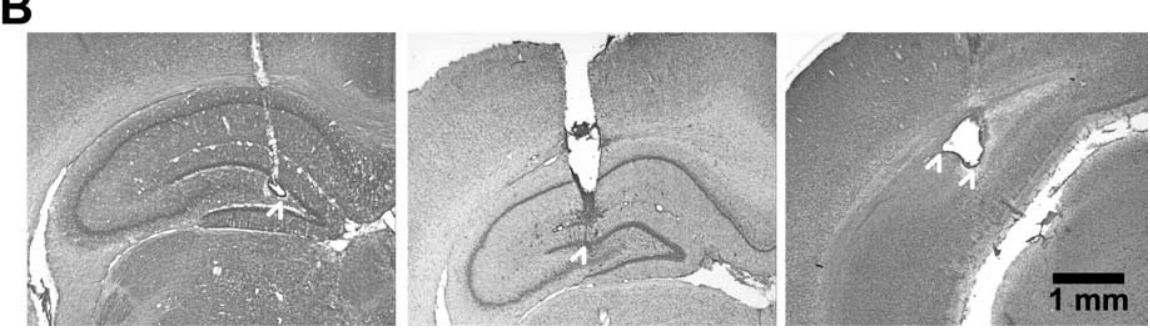

Figure 4. Infusion sites and electrode placements in the hippocampus. $\boldsymbol{A}$, Experiment 3: approximate locations of infusion (c) electrodes (squares), and recording electrodes (stars) in the left hemisphere, depicted for the different groups -scale coding). Coronal sections are adapted from Paxinos and Watson (1998); the numbers indicate the distance from infusion, and stimulation sites. Recording and stimulation sites were marked by an electrolytic lesion. White arrowheads indicate the approximate locations of the tips of the infusion cannula and the electrodes (note: bipolar stimulating electrode).

of the overall dig time during the $60 \mathrm{~s}$ retrieval phase of the probe trials did not reveal a difference between AP-5 (19.00 $\pm 1.67 \mathrm{~s})$ and ACSF $(19.50 \pm 1.23 \mathrm{~s})$ infusion, regardless of the infusion time point (experiment 3a; ANOVA; main effect of drug and interaction drug by time point, $F_{(1,13)}<1$ ) or between CNQX $(12.82 \pm 1.51 \mathrm{~s})$ and $\operatorname{ACSF}(15.43 \pm 2.04 \mathrm{~s})$ infusion (experiment $\left.3 \mathrm{~b} ; t_{(13)}=1.1 ; p>0.29\right)$.

\section{Histology}

The tips of the infusion cannulas were located within the posterior dorsal hippocampus (Fig. 4).

\section{Experiment 4}

Effects of CNQX and AP-5 on low-frequency transmission (experiment 4a)

Transmission at perforant-path synapses onto dentate granule cells was markedly reduced after hippocampal CNQX infusion but mostly unaffected by AP-5 infusion (Fig. $5 A$ ). The absolute values of the baseline EPSP slopes before infusion did not differ across infusion groups (ACSF, $4.33 \pm 0.45 \mathrm{mV} / \mathrm{ms}$; AP-5, $4.39 \pm$ 

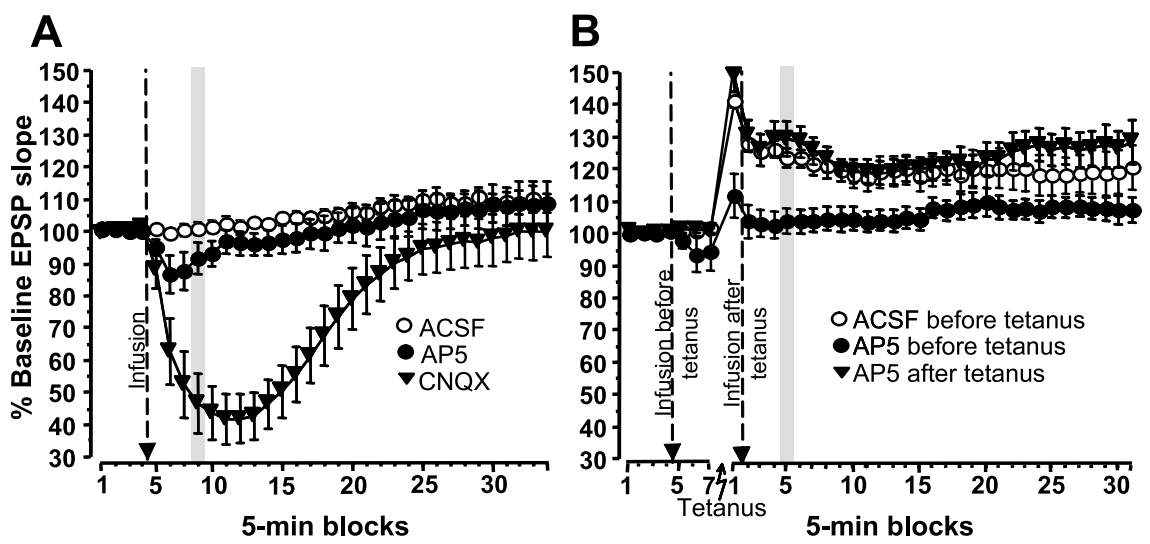

Figure 5. Effects of hippocampal AP-5 and CNQX infusions on synaptic transmission and plasticity (experiment $4, n=6-7$ rats per group). EPSPs in the dentate gyrus evoked by low-frequency stimulation of the perforant path were recorded in anesthetized rats. Data are presented in $5 \mathrm{~min}$ blocks as a percentage of the average EPSP slope during the $20 \mathrm{~min}$ baseline recordings preceding the first infusion (percentage of baseline EPSP slope; mean \pm 1 SEM). ACSF ( $1 \mu \mathrm{l}), \mathrm{D}-\mathrm{AP}-5$ (30 mm, $1 \mu \mathrm{l})$, or CNQX (3 mM, $1 \mu \mathrm{l})$ were infused the times indicated by the arrows. $\boldsymbol{A}$, Effects of hippocampal ACSF, D-AP-5, or CNQX infusions on basal (lowfrequency) synaptic transmission. The vertical gray bar indicates 15-20 min after infusion, corresponding to the time during which the encoding or retrieval phase took place after the hippocampal infusions in experiment 3. $\boldsymbol{B}$, Effects of hippocampal ACSF or AP-5 infusions on induction or maintenance of LTP. The gray bar indicates $20-25 \mathrm{~min}$ after tetanization, corresponding to the delay between encoding and retrieval in experiment 3 .

$0.51 \mathrm{mV} / \mathrm{ms}$; CNQX, $\left.5.11 \pm 1.31 \mathrm{mV} / \mathrm{ms} ; F_{(2,16)}<1\right)$. ANOVA of the normalized EPSP slopes revealed main effects of the infusion group $\left(F_{(2,16)}=7.9 ; p<0.005\right)$ and 5 min blocks $\left(F_{(32,512)}=\right.$ 27.5; $p<0.0001)$, as well as an interaction of both factors $\left(F_{(64,512)}=12.6 ; p<0.0001\right)$. The interaction mainly reflected that, after infusion, there was a marked temporary reduction of the EPSP slope in the CNQX groups compared with the AP-5 and ACSF groups. Separate ANOVA of EPSP slopes 15-20 min after infusion (Fig. $5 A$, gray bar), approximately corresponding to the time during which the encoding or retrieval phase took place after the infusions in experiment 2 , yielded a group effect $\left(F_{(2,16)}\right.$ $=18.2 ; p<0.0001)$. Post hoc tests showed that the EPSP slope was lower in the CNQX group ( $46.40 \pm 9.32 \%$ of baseline) than in both the ACSF $(100.66 \pm 1.93 \% ; p<0.0001)$ and AP-5 (91.01 \pm $4.87 \% ; p<0.0005)$ groups, which did not differ $(p>0.35)$.

\section{Effects of AP-5 on induction and maintenance of LTP}

(experiment $3 b$ )

Hippocampal AP-5 infusion completely blocked the induction of LTP without affecting its maintenance or expression (Fig. 5B). The absolute values of the baseline EPSP slopes did not differ across infusion groups (ACSF, $5.86 \pm 1.25 \mathrm{mV} / \mathrm{ms}$; AP-5, $6.04 \pm$ $1.05 \mathrm{mV} / \mathrm{ms}$; post-AP-5, $4.85 \pm 0.70 \mathrm{mV} / \mathrm{ms} ; F_{(2,16)}<1$ ). ANOVA of the normalized EPSP slopes revealed main effects of the infusion group $\left(F_{(2,16)}=5.3 ; p<0.02\right)$ and 5 min blocks $\left(F_{(37,592)}=30.2 ; p<0.0001\right)$, as well as an interaction of both factors $\left(F_{(74,512)}=3.4 ; p<0.0001\right)$. This mainly reflected that, after tetanization, the EPSP slope in the ACSF and the post-AP-5 group showed pronounced LTP, whereas in the AP-5 group receiving infusion before tetanization, there was only a small posttetanic potentiation lasting $\sim 5 \mathrm{~min}$. A separate ANOVA of EPSP slopes 20-25 min after tetanization (Fig. 5B, gray bar), corresponding to the $20-25$ min that passed after the encoding phase in experiment 2 until the rats had to use the place memory in the retrieval phase, yielded a group effect $\left(F_{(2,16)}=9.3 ; p<0.0025\right)$. Post hoc comparisons demonstrated that EPSP slopes were markedly potentiated in the ACSF $(123.62 \pm 2.89 \%$; $p<0.01)$ and post-AP-5 (129.34 $\pm 5.42 \% ; p<0.001)$ groups compared with the AP-5 group (103.87 $\pm 3.88 \%)$.
Electroencephalogram

In the samples that were analyzed, the dentate gyrus EEG was dominated by occasional theta activity at a frequency of 2-6 $\mathrm{Hz}$, as typically observed in urethaneanesthetized rats (Buzsáki et al., 1986). Glutamatergic transmission in the hippocampus, generated, for example, by perforant-path input, may contribute to the hippocampal EEG, but a substantial portion of the EEG may be independent of such transmission (Heynen and Bilkey, 1994; Buzsáki, 2002; Leung and Shen, 2004). Even though recordings under urethane anesthesia may underestimate such contributions because of the attenuation of the perforant-path input by the anesthetic (Buzsáki, 2002), inspection of power spectra generated from the EEG recordings in the present study did not reveal effects of hippocampal CNQX or AP-5 infusion on dentate gyrus theta (data not shown).

\section{Histology}

The tips of the infusion cannulas were located within the posterior dorsal hippocampus. All recording sites were located in the hilar region of the dorsal hippocampus, either just below the upper or just above the lower granule cell layer of the dentate gyrus, and the stimulation sites were in the angular bundle (Fig. 4).

\section{Discussion}

This study developed and characterized a food-rewarded task in the event arena to study encoding and retrieval of one-trial allocentric place memory; memory declined with increasing retention delay, still being significant after $6 \mathrm{~h}$ (experiments 1 and 2). Hippocampal infusion of the NMDA receptor antagonist AP-5 selectively blocked encoding; retrieval was impaired by the AMPA receptor antagonist CNQX (experiment 3). It was also confirmed that, infused into the hippocampus exactly as in the behavioral studies, AP-5 selectively blocked LTP induction, whereas CNQX reduced fast excitatory transmission at perforant-path dentate gyrus synapses (experiment 4).

\section{The novel one-trial place memory task}

Rats must encode a memory of a trial-specific place in a familiar environment and, after a 5 min to 6 h delay, retrieve this memory to efficiently obtain food reward in an open arena. Performance in probe trials, with food omitted from the sandwells during retrieval, demonstrated no reliance on food odors. Rats may use both relationships among multiple environmental cues and elemental cues, such as odor traces and directional or idiothetic cues, to find a place (Eichenbaum et al., 1990; Hodges, 1996; Jacobs and Schenk, 2003; Jeffrey, 2003). In the present study, the different start positions for encoding and retrieval phases rendered idiothetic or directional cues unhelpful. The disruption of retrieval in the dark and the lack of an effect of arena rotation established the importance of visual cues. Altogether, it is warranted to conclude that the task requires visuospatial relational memory based on one single experience. The protocol resembles tests of viewpoint-independent place memory that were developed to study aspects of episodic memory and hippocampal 
function in humans (Holdstock et al., 2000; Burgess et al., 2002). It complements one-trial place memory tasks in the water maze (Steele and Morris, 1999; Nakazawa et al., 2003), which have very different sensorimotor demands and require aversively motivated escape, as well as in the radial arm maze (Floresco et al., 1997; Lee and Kesner, 2002), which favor the use of directional and idiothetic cues (Hodges, 1996; Jacobs and Schenk, 2003).

The task represents an extension of procedures developed in the cheeseboard apparatus (Gilbert et al., 1998, 2001; Kirwan et al., 2005). These rely on correct first choices accumulated over many trials to measure one-trial place memory, whereas in our paradigm, the dig-time and error measures allow the assessment of performance on discrete trials, a prerequisite for the separate study of encoding and retrieval mechanisms. Finally, because of similar procedural demands, mechanisms of one-trial place memory examined in the novel task can be compared directly with those in the previously developed one-trial flavor-place memory task (Day et al., 2003).

\section{Distinct behavioral and electrophysiological effects of hippocampal NMDA and AMPA receptor blockade}

AP-5 infusion before encoding resulted in chance performance, whereas infusion after encoding left performance intact. These results extend findings of previous studies, using pharmacological and molecular-genetic techniques, that hippocampal NMDA receptors are required for one-trial place memory (Steele and Morris, 1999; Lee and Kesner, 2002; Nakazawa et al., 2003). Specifically, they reveal that these receptors contribute to the encoding but not retrieval of such memory. Our findings do not speak to the role of hippocampal NMDA receptors in memory consolidation after encoding (Packard and Teather, 1997; Shimizu et al., 2000; Rossato et al., 2004), because we had no sufficiently delayed retrieval test.

In vitro experiments have established that hippocampal NMDA receptors are critical for the induction of LTP but of minor importance for low-frequency synaptic transmission (Bliss and Collingridge, 1993). In vivo recordings demonstrated that hippocampal AP-5 infusion impairs the induction of hippocampal LTP (Errington et al., 1987; Morris et al., 1989; Lee and Kesner, 2002), but marked reductions in low-frequency transmission have also been reported (Walker and Gold, 1994). Our recordings from perforant-path dentate gyrus synapses in urethane-anesthetized rats established that AP-5, infused into the hippocampus exactly as in our behavioral experiments, selectively blocked LTP induction. Comparable effects likely occurred at excitatory synapses in subfields CA1-CA3, because these synapses (except for mossy fiber synapses) show NMDA receptordependent LTP (Bliss and Collingridge, 1993; Lee and Kesner, 2002) and CA1-CA3 and dentate gyri were similarly close to the infusion sites; moreover AP-5, infused as in the present study, diffuses evenly throughout the dorsal hippocampal subfields (Steele and Morris, 1999). Altogether, our results suggest that NMDA receptor-mediated induction of hippocampal synaptic plasticity contributes to encoding but not retrieval of one-trial place memory. Interestingly, induction of LTP at intrinsic hippocampal pathways creates new hippocampal place fields, which are stable for about $6 \mathrm{~h}$ (Dragoi et al., 2003); such place fields may be neural correlates of the place representations underlying performance in our task.

CNQX infusion before retrieval impaired performance, and CNQX reduced fast excitatory transmission at perforant-path dentate gyrus synapses; comparable effects probably occurred at other intrinsic hippocampal synapses [as demonstrated for the
AMPA receptor antagonist LY326325 (Riedel et al., 1999)]. Retrieval was not blocked completely. This may reflect that, even close to the infusion site, excitatory synaptic transmission was reduced by only $\sim 50 \%$ at the time of testing (Fig. $5 \mathrm{~A}$ ). Although we did not test CNQX infusions before encoding (for the reasons described for experiment 3 in Materials and Methods), AMPA receptor-mediated synaptic transmission is necessary to enable the NMDA receptor-mediated hippocampal encoding mechanisms (Bliss and Collingridge, 1993). Our findings are consistent with the idea that hippocampal AMPA receptors, being critical for low-frequency synaptic transmission (Davies and Collingridge, 1989; Lambert and Jones, 1990), contribute to both encoding and retrieval of place memory (Riedel et al., 1999).

\section{Theoretical implications}

The present findings are consistent with notions holding that rapid encoding of a stimulus pattern into relational memory, such as allocentric place memory, requires the induction of hippocampal synaptic plasticity, and the subsequent retrieval requires excitatory hippocampal transmission to activate the stored pattern representation after perceiving a part of this pattern (see Introduction). Additionally, hippocampal synaptic transmission may mediate the use of hippocampal memory by relating it to mechanisms of response and motor control via hippocampal connections to subcortical sites and the prefrontal cortex (Floresco et al., 1997; Bast and Feldon, 2003; Bannerman et al., 2004; Peleg-Raibstein et al., 2005). In contrast, rats can incrementally acquire place memory and later retrieve it despite impaired hippocampal synaptic plasticity (Bannerman et al., 1995; Saucier and Cain, 1995; Otnaess et al., 1999; Reisel et al., 2002; Schmitt et al., 2003) and even with the hippocampus completely lesioned (Morris et al., 1990; Hunt et al., 1994).

Alternative accounts are less consistent with the present findings. The particular sensitivity of one-trial place learning to treatments blocking hippocampal LTP argues against a function of hippocampal LTP-like synaptic plasticity as an "attentional device" (Shors and Matzel, 1997), because this would imply that blockade of synaptic plasticity should not impair one-trial learning [as outlined by Fanselow (1997)]. State dependence, the dependence of memory retrieval on the congruity between the brain states during encoding and retrieval (Overton, 1964; Millin et al., 2001), is also unlikely to account for our data. AP-5 infusions before encoding prevented retrieval $20 \mathrm{~min}$ later when the drug was still active in the hippocampus (as evidenced by blockade of LTP induction 2-3 h after infusion; T. Bast, unpublished observations). AP-5 infusions before retrieval left performance intact, despite encoding in a drug-free state. Finally, the different effects of AP-5 infusions before and after encoding and the absence of consistent gross sensorimotor impairments or differences in overall dig time, both after AP-5 and after CNQX infusions, argue against the possibility that the infusions interfered with motivational and sensorimotor task demands.

In radial-arm maze experiments, rats acquired and maintained trial-specific place information in a familiar environment over delays of minutes to hours independent of hippocampal NMDA receptors (Shapiro and O'Connor, 1992; Caramanos and Shapiro, 1994; Kesner and Rolls, 2001). This may reflect that representations of elemental stimuli, such as idiothetic and directional cues, supported place memory. Furthermore, in the radial arm maze, there are typically only eight places potentially containing reward (compared with 32 in our arena), so that the rats become highly familiar with these places throughout training. Under these circumstances, attractor states of hippocampal ac- 
tivity representing the familiar places may be established during training and support one-trial place memory with no further induction of synaptic plasticity necessary during later trials (Kesner and Rolls, 2001).

\section{Implications for episodic-like memory}

Recently developed episodic-like memory tasks in rats, requiring integrated one-trial memory of events, their places, and their temporal context, depend on the hippocampus (Clayton et al., 2003; Day et al., 2003; Eacott and Norman, 2004; Ergorul and Eichenbaum, 2004) [as human episodic memory (Tulving, 2002)]. The contributions of hippocampal AMPA and NMDA receptors to one-trial place memory revealed here are probably important for episodic-like memories containing a one-trial place component. For example, they may partly explain the requirement of these receptors for one-trial flavor-place memory (Day et al., 2003). However, hippocampal NMDA receptors are critical for rapid encoding of relational memory without a place component (Roberts and Shapiro, 2002) and may generally contribute to binding distinct aspects of episodic-like memory, such as flavor and place information, into relational representations (Eichenbaum et al., 1999; Eichenbaum, 2004). The hippocampal dorsoventral differentiation could help in dissecting the different hippocampal contributions to episodic-like memory. For example, the dorsal hippocampus, receiving most of the hippocampal visuospatial afferents, may be more important than the ventral hippocampus for encoding one-trial place memory (Moser and Moser, 1998; Bannerman et al., 2004). In contrast, with substantial olfactory and gustatory input reaching the ventral hippocampus (Moser and Moser, 1998; Petrovich et al., 2001), dorsoventral interactions may be required to bind place and flavor information.

\section{References}

Aggleton JP, Pearce JM (2001) Neural systems underlying episodic memory: insights from animal research. Philos Trans R Soc Lond B Biol Sci 356:1467-1482.

Bannerman DM, Good MA, Butcher SP, Ramsay M, Morris RG (1995) Distinct components of spatial learning revealed by prior training and NMDA receptor blockade. Nature 378:182-186.

Bannerman DM, Rawlins JNP, McHugh SB, Deacon RMJ, Yee BK, Bast T, Zhang W-N, Pothuizen HHJ, Feldon J (2004) Regional dissociations within the hippocampus-memory and anxiety. Neurosci Biobehav Rev 273-283.

Bast T, Feldon J (2003) Hippocampal modulation of sensorimotor processes. Prog Neurobiol 70:319-345.

Bast T, DaSilva BM, Morris RGM (2004a) Distinct contributions of hippocampal NMDA and AMPA receptors to encoding and retrieval of onetrial place memory. FENS Abstr 2:A112.5.

Bast T, DaSilva BM, Morris RGM (2004b) Dissecting episodic-like memory in rats: 1-trial place memory in an event arena. Soc Neurosci Abstr 30:205.5.

Bliss TVP, Collingridge GL (1993) A synaptic model of memory: long-term potentiation in the hippocampus. Nature 361:31-39.

Bures J, Fenton AA (2000) Neurophysiology of spatial cognition. News Physiol Sci 15:233-240.

Burgess N, Maguire EA, O'Keefe J (2002) The human hippocampus and spatial and episodic memory. Neuron 35:625-641.

Buzsáki G (2002) Theta oscillations in the hippocampus. Neuron 33:325-340.

Buzsáki G, Czopf J, Kondákor I, Kellényi L (1986) Laminar distribution of hippocampal rhytmic slow activity (RSA) in the behaving rat: currentsource density analysis, effects of urethane and atropine. Brain Res 365:125-137.

Caramanos Z, Shapiro ML (1994) Spatial memory and N-methyl-Daspartate receptor antagonists APV and MK-801: memory impairments depend on familiarity with the environment, drug dose, and training duration. Behav Neurosci 108:30-43.
Clayton NS, Dickinson A (1998) Episodic-like memory during cache recovery by scrub jays. Nature 395:272-274.

Clayton NS, Krebs JR (1994) One-trial associative memory: comparison of food storing and nonstoring species of birds. Anim Learn Behav 22:366-372.

Clayton NS, Bussey TJ, Dickinson A (2003) Can animals recall the past and plan for the future? Nat Rev Neurosci 4:685-691.

Davies SN, Collingridge GL (1989) Role of excitatory amino acid receptors in synaptic transmission in area CAl of rat hippocampus. Proc R Soc Lond B Biol Sci 236:373-384.

Day M, Langston R, Morris RGM (2003) Glutamate-receptor-mediated encoding and retrieval of paired-associate learning. Nature 424:205-209.

Dragoi G, Harris KD, Buzsáki G (2003) Place representation within hippocampal networks is modified by long-term potentiation. Neuron 39:843-853.

Eacott MJ, Norman G (2004) Integrated memory for object, place, and context in rats: a possible model of episodic-like memory? J Neurosci 24:1948-1953.

Eichenbaum H (2004) Hippocampus: cognitive processes and neural representations that underlie declarative memory. Neuron 44:109-120.

Eichenbaum H, Stewart C, Morris RGM (1990) Hippocampal representation in place learning. J Neurosci 10:3531-3542.

Eichenbaum H, Dudchenko P, Wood E, Shapiro M, Tanila H (1999) The hippocampus, memory, and place cells: is it spatial memory or a memory space? Neuron 23:209-226.

Ergorul C, Eichenbaum H (2004) The hippocampus and memory for "what," "where," and "when." Learn Mem 11:397-405.

Errington ML, Lynch MA, Bliss TVP (1987) Long-term potentiation in the dentate gyrus: induction and increased glutamate release are blocked by D(-)aminophosphonovalerate. Neuroscience 20:279-284.

Fanselow MS (1997) Without LTP the learning circuit is broken. Behav Brain Sci 20:616.

Floresco SB, Seamans JK, Phillips AG (1997) Selective role for hippocampal, prefrontal cortical, and ventral striatal circuits in radial-arm maze tasks with or without delay. J Neurosci 17:1880-1890.

Gaffan D (1991) Spatial organization of episodic memory. Hippocampus 3:262-264.

Gilbert PE, Kesner RP, DeCoteau WE (1998) Memory for spatial location: role of the hippocampus in mediating spatial pattern separation. J Neurosci 18:804-810.

Gilbert PE, Kesner RP, Lee I (2001) Dissociating hippocampal subregions: a double dissociation between dentate gyrus and CA1. Hippocampus 11:626-636.

Healy SD, Krebs JR (1992) Spatial memory in tits: recalling a single positive location. Anim Learn Behav 20:121-126.

Heynen AJ, Bilkey DK (1994) Effects of perforant path procaine on hippocampal type 2 rhythmical slow-wave activity (theta) in the urethaneanesthetized rat. Hippocampus 4:683-695.

Hodges H (1996) Maze procedures: the radial-arm and water maze compared. Cogn Brain Res 3:167-181.

Holdstock JS, Mayes AR, Cezayirli E, Isaac CL, Aggleton JP, Roberts N (2000) A comparison of egocentric and allocentric spatial memory in a patient with selective hippocampal damage. Neuropsychologia 38:410-425.

Hunt ME, Kesner RP, Evans RB (1994) Memory for spatial location: functional dissociation of entorhinal cortex and hippocampus. Psychobiology 22:186-194.

Jacobs LF, Schenk F (2003) Unpacking the cognitive map: the parallel map theory of hippocampal function. Psychol Rev 110:285-315.

Jeffrey KJ, ed. (2003) The neurobiology of spatial behaviour. Oxford: Oxford UP.

Kesner RP, Rolls ET (2001) Role of long-term synaptic modification in short-term memory. Hippocampus 11:240-250.

Kesner RP, Farnsworth G, DiMattis BV (1989) Double dissociation of egocentric and allocentric space following medial prefrontal and parietal cortex lesions in rats. Behav Neurosci 103:956-961.

Kirwan CB, Gilbert PE, Kesner RP (2005) The role of the hippocampus in the retrieval of a spatial location. Neurobiol Learn Mem 83:65-71.

Lambert JDC, Jones RSG (1990) A reevaluation of excitatory amino acidmediated synaptic transmission in rat dentate gyrus. J Neurophysiol 64:119-132.

Lee I, Kesner RP (2002) Differential contribution of NMDA receptors in 
hippocampal subregions to spatial working memory. Nat Neurosci 5:162-168.

Leung LS, Shen B (2004) Glutamatergic synaptic transmission participates in generating hippocampal EEG. Hippocampus 14:510-525.

Martin SJ (1998) Time-dependent reversal of dentate LTP by $5 \mathrm{~Hz}$ stimulation. NeuroReport 9:3775-3781.

Martin SJ (2001) Activation of metabotropic glutamate receptors induces gamma frequency oscillations in the rat dentate gyrus in vivo. Neuropharmacology 40:634-637.

Martin SJ, Grimwood PD, Morris RGM (2000) Synaptic plasticity and memory: an evaluation of the hypothesis. Annu Rev Neurosci 23:649-711.

Matus-Amat P, Higgins EA, Barrientos RM, Rudy JW (2004) The role of the dorsal hippocampus in the acquisition and retrieval of context memory representations. J Neurosci 24:2431-2439.

Millin PM, Moody EW, Riccio DC (2001) Interpretations of retrograde amnesia: old problems redux. Nat Rev Neurosci 2:68-70.

Morris RGM, Halliwell RF, Bowery N (1989) Synaptic plasticity and learning II: do different kinds of plasticity underlie different kinds of learning? Neuropsychologia 27:41-59.

Morris RGM, Schenk F, Tweedie F, Jarrard LE (1990) Ibotenate lesions of hippocampus and/or subiculum: dissociating components of allocentric spatial learning. Eur J Neurosci 2:1016-1028.

Morris RGM, Moser EI, Riedel G, Martin SJ, Sandin J, Day M, O'Carrol C (2003) Elements of a neurobiological theory of the hippocampus: the role of activity-dependent synaptic plasticity in memory. Philos Trans R Soc Lond B Biol Sci 358:783-786.

Moser M-B, Moser EI (1998) Functional differentiation in the hippocampus. Hippocampus 8:608-619.

Nadel L, Hardt O (2004) The spatial brain. Neuropsychology 18:473-476.

Nakazawa K, Sun LD, Quirk MC, Rondi-Reig L, Wilson MA, Tonegawa S (2003) Hippocampal CA3 NMDA receptors are crucial for memory acquisition of one-time experience. Neuron 38:305-315.

Nakazawa K, McHugh T, Wilson MA, Tonegawa S (2004) NMDA receptors, place cells and hippocampal spatial memory. Nat Rev Neurosci 5:361-372.

O'Keefe J, Nadel L (1978) The hippocampus as a cognitive map. Oxford: Oxford UP.

O’Reilly RC, Rudy JW (2001) Conjunctive representations in learning and memory: principles of cortical and hippocampal function. Psychol Rev 108:311-345.

Otnaess MK, Brun VH, Moser M-B, Moser EI (1999) Pretraining prevents spatial learning impairment after saturation of hippocampal long-term potentiation. J Neurosci 19:RC49(1-5).

Overton DA (1964) State-dependent or dissociated learning produced with pentobarbital. J Comp Physiol Psychol 57:3-12.

Packard MG, Teather LA (1997) Double dissociation of hippocampal and dorsal-striatal memory by post-training intracerebral injections of 2-amino-5-phosphonopentanoic acid. Behav Neurosci 111:543-551.

Paxinos G, Watson C (1998) The rat brain in stereotaxic coordinates. San Diego: Academic.
Peleg-Raibstein D, Pezze MA, Zhang W-N, Ferger B, Murphy CA, Feldon J, Bast $\mathrm{T}$ (2005) Activation of dopaminergic neurotransmission in the medial prefrontal cortex by NMDA stimulation of the ventral hippocampus in rats. Neuroscience 132:219-232.

Petrovich GD, Canteras NS, Swanson LW (2001) Combinatorial amygdalar inputs to hippocampal domains and hypothalamic behavior systems. Brain Res Rev 38:247-289.

Reisel D, Bannerman DM, Schmitt WB, Deacon RMJ, Flint J, Borchard T, Seeburg PH, Rawlins JNP (2002) Spatial memory dissociations in mice lacking GluR1. Nat Neurosci 5:868-873.

Riedel G, Micheau J, Lam AGM, Roloff EL, Martin SJ, Bridge H, de Hoz L, Poeschel B, McCulloch J, Morris RGM (1999) Reversible neural inactivation reveals hippocampal participation in several memory processes. Nat Neurosci 2:898-905.

Roberts M, Shapiro ML (2002) NMDA receptor antagonists impair memory for nonspatial, socially transmitted food preference. Behav Neurosci 116:1059-1069.

Rossato JL, Bonini JS, Coitinho AS, Vianna MR, Medina JH, Cammarota M, Izquierdo I (2004) Retrograd amnesia induced by drugs acting on different molecular systems. Behav Neurosci 118:563-568.

Saucier D, Cain DP (1995) Spatial learning without NMDA receptor dependent long-term potentiation. Nature 378:186-189.

Schmitt WB, Deacon RMJ, Seeburg PH, Rawlins JNP, Bannerman DM (2003) A within-subjects, within-task demonstration of intact spatial reference memory and impaired spatial working memory in glutamate receptor-A-deficient mice. J Neurosci 23:3953-3959.

Shapiro ML, O'Connor C (1992) N-methyl-D-aspartate receptor antagonist MK-801 and spatial memory representation: working memory is impaired in an unfamiliar environment but not in a familiar environment. Behav Neurosci 106:604-612.

Shimizu E, Tang YP, Rampon C, Tsien JZ (2000) NMDA receptordependent synaptic reinforcement as a crucial process for memory consolidation. Science 290:395-401.

Shors TJ, Matzel LD (1997) Long-term potentiation: what's learning got to do with it? Behav Brain Sci 20:597-655

Steele RJ, Morris RGM (1999) Delay-dependent impairment of a matchingto-place task with chronic and intrahippocampal infusion of the NMDAantagonist D-AP-5. Hippocampus 9:118-136.

Tulving E (2002) Episodic memory: from mind to brain. Annu Rev Psychol 53:1-25.

Walker DL, Gold PE (1994) Intrahippocampal administration of both the D- and the L-isomers of AP-5 disrupt spontaneous alternation behavior and evoked potentials. Behav Neur Biol 62:151-162.

Watkins JC, Krogsgaard-Larsen P, Honoré T (1990) Structure-activity relationships in the development of excitatory amino acid receptor agonists and competitive antagonists. Trends Pharmacol Sci 11:25-33.

Wiltgen BJ, Fanselow MS (2003) A model of hippocampal-corticalamygdala interactions based on contextual fear conditioning. In: The neurobiology of spatial behaviour (Jeffrey KJ, ed), pp 83-103. Oxford: Oxford UP. 